\title{
Dental Side Effects of Long-Term Obstructive Sleep Apnea Therapy: A Comparison of Three Therapeutic Modalities
}

Julia A.M. Uniken Venema, DMD ${ }^{1,2,3}$; Cornelis Stellingsma, DMD, PhD'; Michiel H.J. Doff, MD, DMD, PhD; Aarnoud Hoekema, MD, DMD, PhD $1,2,3,4$

\begin{abstract}
${ }^{1}$ Department of Oral and Maxillofacial Surgery, University Medical Center Groningen, University of Groningen, Groningen, The Netherlands; ${ }^{2}$ Department of Oral Kinesiology, Academic Centre for Dentistry Amsterdam (ACTA), MOVE Research Institute Amsterdam, University of Amsterdam and VU University Amsterdam, Amsterdam, The Netherlands; ${ }^{3}$ Department of Oral and Maxillofacial Surgery, Academic Medical Center (AMC), Amsterdam, The Netherlands; ${ }^{4}$ Department of Oral and Maxillofacial Surgery, Tjongerschans Hospital, Heerenveen, The Netherlands
\end{abstract}

\begin{abstract}
Study Овјестіves: Obstructive sleep apnea (OSA) is a sleep-related breathing disorder characterized by repetitive obstruction of the upper airway during sleep. Patients are often treated with either continuous positive airway pressure (CPAP) or a mandibular advancement device (MAD). The objective of this study was to evaluate changes in dental occlusion, associated with long-term MAD and CPAP therapy.

MeThoDs: Patients with OSA who used a bilateral thrust MAD $(n=31)$ were matched with a patient group from a previous randomized trial evaluating the dental side effects of an anterior traction MAD and CPAP therapy. Changes in dental occlusion were analyzed from dental plaster casts taken at baseline and after 2 years of treatment.

RESULTs: The number of occlusal contact points in the (pre)molar region significantly decreased in all treatment groups (MAD groups; $P<.01)$ (CPAP group; $P=.03$ ). The changes in overbite and anterior-posterior movement was significantly different between the anterior traction MAD and CPAP group $(P<.01)$ and between both MAD groups (overbite; $P=.01$, anterior-posterior movement; $P<.01)$. The anterior traction MAD group was associated with more pronounced occlusal changes when compared with the bilateral thrust MAD group.
\end{abstract}

ConcLusions: Significant changes in dental occlusion are seen following 2 years with both MAD and CPAP therapy. Specific features in oral appliance design may affect the extent of changes in dental occlusion.

KEYWORDS: continuous positive airway pressure, mandibular advancement devices, obstructive sleep apnea, side effects

Citation: Venema JA, Stellingsma C, Doff MH, Hoekema A. Dental side effects of long-term obstructive sleep apnea therapy: a comparison of three therapeutic modalities. Journal of Dental Sleep Medicine. 2018;5(2):39-46.

\section{INTRODUCTION}

Obstructive sleep apnea (OSA) is a sleep-related breathing disorder characterized by repetitive obstructions of the upper airway during sleep. ${ }^{1-3}$ During sleep the muscle tone of the upper airway decreases and the airway trembles or collapses. OSA can be diagnosed when patients have five or more partial obstructions (hypopneas) and/or complete obstructions (apneas) of the upper airway per hour of sleep. The number of apneas and hypopneas per hour of sleep are quantified by the apnea-hypopnea index (AHI). ${ }^{3-6} \mathrm{OSA}$ is a sleep-related breathing disorder associated with excessive daytime sleepiness and an increased risk of cardiovascular disease that usually requires a lifelong treatment..$^{7-10}$

The precise treatment of OSA depends on the severity of symptoms and disease, and the patient's anatomical characteristics and health status. ${ }^{11}$ There are several treatment options for OSA, including lifestyle changes, continuous positive airway pressure (CPAP), a mandibular advancement device (MAD), and upper airway surgery. ${ }^{12}$

CPAP is generally applied through a nasal mask. As a result of this positive pressure, the upper airway is pneumatically splinted and obstructed breathing events are prevented..$^{13-15}$
CPAP is usually very effective in reducing the number of apneas, but may be complicated by suboptimal acceptance and adherence in a relatively high proportion of patients..$^{8,16-18}$

A MAD is possibly a more patient friendly alternative to CPAP, especially in patients with mild to moderate disease. In order to prevent upper airway obstructions, a MAD is designed to advance the mandible in a more forward position. A MAD improves upper airway patency by pulling the tongue base, epiglottis and soft palate forward. In addition, MAD therapy has been shown to stimulate the musculature of the palate, tongue base and pharynx, resulting in a decreased upper airway resistance. ${ }^{19,20}$ Acceptance of and therapeutic outcome with a MAD is favorable in many patients, especially in the treatment of mild to moderate OSA. ${ }^{6,821-23}$ However, mild and transient side effects have been reported in the initial period of therapy. These may include tooth pain, myofascial pain, temporomandibular joint pain, excessive salivation or a dry mouth, and gum irritation. $^{21,24-28}$ Long-term MAD use is associated with changes in craniofacial morphology $y^{26,27}$ as well as changes in dental occlusion, including a reduction in overjet, overbite, and the number of occlusal contact points. ${ }^{20,21,25,27,29,30}$ The amount of mandibular protrusion with the MAD has been 
Figure 1- Thornton Adjustable Positioner.

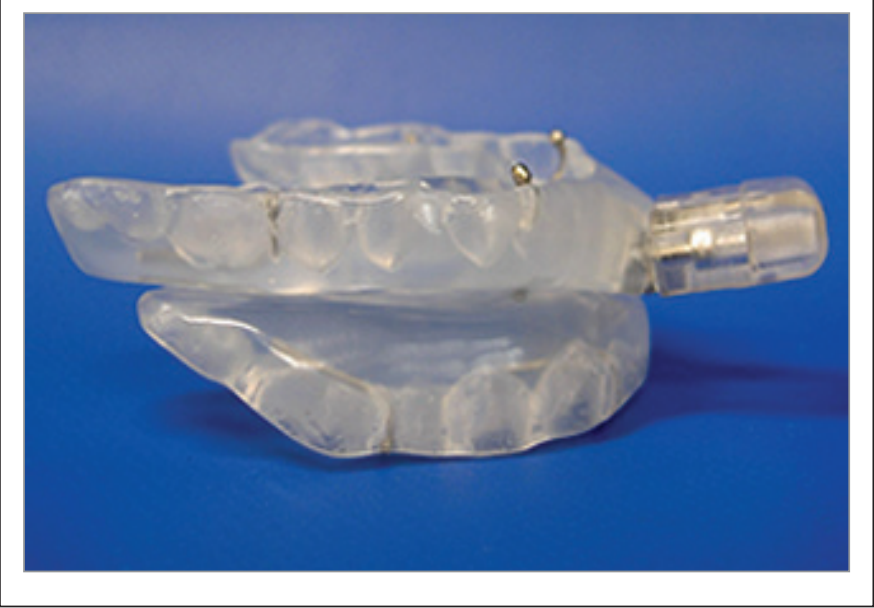

positively correlated with its efficacy. ${ }^{8,31,32}$ However, the more the mandible is positioned anteriorly, the more likely that (dental) side effects will occur., , $33,34^{-1}$

The current study focuses on the effects of MAD and CPAP therapy on dental occlusion. To date it is unknown to what extent different types of MADs cause adverse changes in dental occlusion and how these changes relate to the effects of CPAP therapy on dental occlusion. The objective of the current study is to evaluate the changes in dental occlusion from a bilateral thrust and anterior traction MAD and to compare these outcomes with the dental effects of CPAP therapy.

\section{METHODS}

\section{Patient Selection}

In a previous randomized controlled trial, Doff et al. evaluated the dental side effects of MAD therapy and compared them with CPAP therapy after a 2-year treatment period. ${ }^{29}$ The CPAP system evaluated in this study applied pressure via a nasal mask. ${ }^{29}$ The MAD evaluated in this study was the Thornton Adjustable Positioner (TAP) (Airway Management Inc., Dallas, Texas, United States), an anterior traction MAD. ${ }^{29}$ In the current study the results from this previous study were compared with a third patient group that was retrospectively recruited and used a different type of MAD. The MAD evaluated for this purpose was the SomnoDent appliance (SomnoDent, Somnomed AG, Australia), a bilateral thrust MAD. The TAP (Figure 1) and SomnoDent (Figure 2) appliance differ in the way in which the mandible is protruded. With the TAP this is accomplished by a fixed screw in the front of the appliance, whereas with the SomnoDent this is accomplished with two screw mechanisms in the molar region of the appliance.

Patients in the SomnoDent group were recruited through the Department of Oral and Maxillofacial Surgery of the University Medical Center Groningen - The Netherlands and from the Department of Oral and Maxillofacial Surgery of the Tjongerschans Hospital Heerenveen - The Netherlands. In accordance with the American Academy of Sleep Medicine recommendation, OSA was defined by an AHI higher than 5 and subjective complaints. ${ }^{10}$ In addition, patients were eligible when aged 20

\section{Figure 2-SomnoDent appliance.}

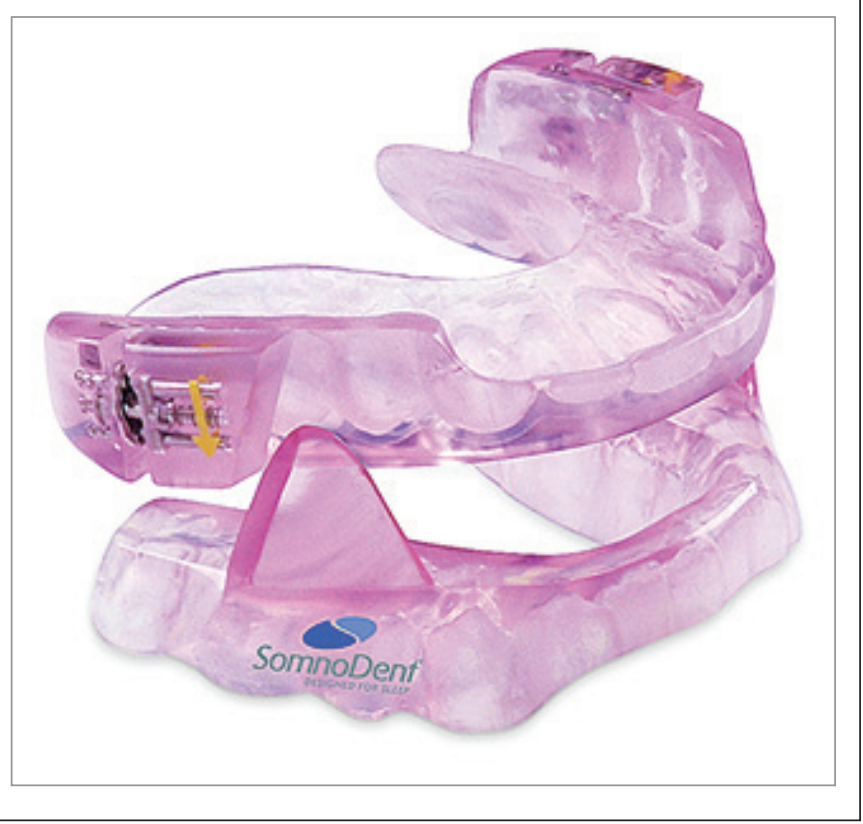

years or older and when they had used a SomnoDent appliance for a 2-to 3-year period for at least 5 nights/wk and $5 \mathrm{~h} /$ night. Patients were excluded when they had previous treatment for their OSA (eg, CPAP or upper airway surgery). The number of patients who met the required follow-up time was 164 . All these patients were checked for the remaining inclusion criteria and invited for participation in this current study. Due to mismatching the inclusion criteria or not responding to the invitation, eventually 31 patients were recruited in the SomnoDent group. The patients in the TAP group $(n=29)$ and CPAP group $(n=34)$ from the study by Doff et al. were recruited through the Department of Home Mechanical Ventilation of the University Medical Center Groningen - the Netherlands. ${ }^{29}$ The two treatment modalities in this study were randomly assigned and followed for a 2-year treatment period. Inclusion and exclusion criteria were similar for all three treatment groups. ${ }^{29}$ All patients using an oral appliance in the current study had been treated by the same clinician.

\section{Study Design}

At baseline all patients had been subjected to a polysomnographic evaluation. The data in the SomnoDent group were longitudinally and retrospectively obtained. The data in the TAP and CPAP group were longitudinally and prospectively obtained.

The degree of protrusion in both MAD groups at baseline was set at $50 \%$ to $70 \%$ of the patient's maximum protrusion. Patients using the SomnoDent could change the degree of protrusion by means of two propulsion screws in the (pre) molar region in the upper part of the appliance. Patients using the TAP could adjust mandibular protrusion by means of a screw mechanism incorporated in the anterior part of the upper appliance. If patients still experienced subjective OSA complaints, they were instructed to advance the mandible. Patients were instructed to advance their mandible until 
symptoms abated or until further protrusion of the mandible resulted in discomfort while wearing the appliance.

After an 8-week habituation and adjustment period in all three treatment groups a polysomnographic evaluation study was performed to evaluate treatment efficacy. If this study showed a residual OSA, treatment was further adjusted if possible. Subsequently, after a 4-week period, another polysomnographic evaluation was performed.

Treatment was considered successful if AHI was less than 5 or showed a $50 \%$ reduction from the baseline value to a value less than 20 in a patient who had no symptoms while using the therapy. If treatment was not successful an alternative therapy was offered. ${ }^{29}$

\section{Study Model Analysis}

At baseline and after a 2- to 3-year treatment period, alginate impressions of the upper and lower dental arches were obtained from each patient. Also, a bite registration in maximum occlusion was obtained by using a vinyl polysiloxane registration material (Exabyte II NDS, GC America Inc, Alsip, Illinois, United States). From these impressions, dental plaster cast study models (GC FUJIROCK EP, GC America Inc, Alsip, Illinois, United States) were made that were set into maximum occlusion in an articulator (Artex, Girrlach Dental, Koblach, Germany) with bilateral sagittal condylar inclination of 32.5 and Bennett angle of 17.5. Measurements on the plaster casts were performed using a digital sliding caliper with a $0.01-\mathrm{mm}$ resolution. The degree of mandibular protrusion in which the MAD was set was measured with the digital sliding caliper when the MAD was fixed in the patient's mouth. Subsequently, the percentage of mandibular protrusion in which the appliance was set was calculated. All measurements were done twice by the same observer. For continuous variables the mean of both measurements was used for further analysis. When models were damaged or if there were not enough teeth for adequate classification, the variable was listed as indefinable. ${ }^{29}$

Occlusal contact points were determined by using vinyl polysiloxane registration material (Exabite II NDSTM, GC America Inc, Alsip, Illinois, United States) directly on the cast models in maximum occlusion. Biting force or the size of the contact points were not recorded. The number of occlusal contact points was obtained from the maxillary model in both the cuspid-incisor region and in the (pre)molar region. ${ }^{29}$

Anterior overjet and overbite were measured at both maxillary central incisors, the mean of both was used for further calculations. Anterior overjet was defined as the horizontal distance from the labial plane of the lower central incisor to the mesial end of the incisal edge of the upper central incisor. Anterior overbite was measured as the vertical distance from the incisal edge of the lower central incisor to the incisal edge of the upper central incisor. The difference between the pretreatment and posttreatment overjet and overbite was called delta overjet and overbite. Negative values for delta overjet were defined as a mesial shift of the occlusion, and positive values were defined as a distal shift of the of the occlusion. ${ }^{29}$
Anterior-posterior movement was measured by evaluating the changes in distance between the buccal groove of the mandibular and the maxillary first molars (pretherapeutic values minus posttherapeutic values). Negative values were related to a mesial shift of the occlusion and positive values to a distal shift. If first molars were missing, secondary molars were used. ${ }^{29}$

The Angle classification of malocclusion was used to classify molar and cuspid occlusion and was recorded as Class I/ neutro-occlusion, Class II/disto-occlusion, or Class III/mesioocclusion. ${ }^{35}$ Angle classification was classified as unchanged or changed. The classification was determined at baseline and follow-up at the right and left first molar and cuspid position. When cuspid or molar teeth were missing or damaged, the patient was listed as indefinable. The change of the Angle classification was defined as favorable if it changed toward a neutro-occlusion. ${ }^{29}$

Maxillary and mandibular teeth in the (pre)molar region were used to determine the transversal relation. This relation was determined as normal, end-to-end or crossbite. If the transversal relation had changed at one or more teeth at the (pre)molar region, this was recorded. ${ }^{29}$

Crowding was visually defined as "increased," "decreased" or "no change" in space in the alveolar arch. Evaluation of diastemas was performed and classified as "unchanged," "increased" or "decreased." If teeth were extracted during the follow-up period, they were not counted as interproximal spaces. Dummies were not counted as present permanent teeth, but were included in all analyses. ${ }^{29}$

A skilled and trained professional performed all measurements. Measurements were all performed three times by the same observer who was blinded for the patient's treatment. The mean of the second and third measurement was used for further analysis.

\section{Statistical Analysis}

The Statistical Package for the Social Sciences (SPSS Statistics version 22; IBM Corp., Armonk, New York, United States) was used to perform the analyses. A 95\% confidence interval and the level of significance $a$ was set at 0.05 . The changes in dental occlusion in the SomnoDent group were compared with results from the TAP and CPAP group from the study by Doff et al. ${ }^{29}$

To compare pretreatment and posttreatment variables, paired Student $t$ tests were performed. To compare variables between the three intervention groups, an analysis of variance was done. For comparison of variables that were not normally distributed the Mann-Whitney $U$ test and the Kruskal-Wallis test was used. For categorical variables within and between the three groups, chi-square tests were performed. Finally, linear regression analysis, the Pearson and Spearman correlation test, was used to determine confounders, the relationship between possible dental side effects, and other therapy- or patientrelated variables during the follow-up.

This study was approved by the appropriate ethics committee and has been performed in accordance with the ethical standards laid down in the 1964 Declaration of Helsinki and its later amendments. All persons have given their written informed consent prior to inclusion in this study. 


\section{RESULTS}

\section{Patient Characteristics}

A total of 31 patients were included in the SomnoDent group. In the study by Doff et al. 29 patients were included in the TAP group and 34 patients in the CPAP group. ${ }^{29}$ The mean \pm standard deviation follow-up period in the SomnoDent group was $2.5 \pm 0.3$ years (range 2.0 to 3.3 ), in the TAP group $2.3 \pm 0.2$ years (range 2.1 to 3.1) and in the CPAP group $2.4 \pm 0.3$ years (range 2.1 to 3.2 ). The mean follow-up time was not significantly different between the three groups. ${ }^{29}$ The mean degree of protrusion in de SomnoDent group was $76.7 \% \pm 11.2 \%(n=21)$ and in the TAP group $79.3 \% \pm 19.3 \%(n=29)$. The mean degree of protrusion was not significantly different between the two groups.

In the SomnoDent group the variables baseline AHI, body mass index, nights/wk use and the number of occlusal (pre) molar contact points at baseline, were not normally distributed. A significant difference was observed in body mass index between the SomnoDent $(30.3 \pm 5.6)$ and CPAP group $(33.7 \pm 5.7)(P<.01)$ (Table 1). Also, a significant difference was observed in baseline AHI between the SomnoDent $(17.5 \pm 13.2)$ and TAP group $(35.6 \pm 22.3)(P<.01)$, and between the SomnoDent and CPAP group $(44.2 \pm 5.7)(P<.01)^{29}$ (Table 1). Finally, a significant difference was observed in AHI after 2 to 3 months of treatment between the SomnoDent $(6.9 \pm 5.9)$ and TAP group $(2.9 \pm 3.7)(P<.01)$, and between the SomnoDent and CPAP group $(2.1 \pm 4.0)(P<.01)$ (Table 1$)$.

\section{Study Model Analysis}

When evaluating the number of occlusal contact points, a significant decrease was observed in the (pre)molar region from baseline to follow-up in all three treatment groups (Table 1). A significant reduction in overbite was observed when the treatment groups were compared. A significant difference was observed between the SomnoDent $(-0.6 \pm 0.5)$ and TAP group $(-1.2 \pm 1.1)(P=.01)$, between the SomnoDent and CPAP group $(-0.1 \pm 0.6)(P=.02)$, and between the TAP and CPAP group $(P<.01)$. With respect to the decrease in overjet, a significant difference was observed between the SomnoDent $(-0.6 \pm 0.7)$ and TAP group $(-1.5 \pm 1.5)(P<.01)$ and between the TAP and CPAP group $(-0.2 \pm 0.7)(P<.01)$ (Table 1$)$. The anteriorposterior movement was significantly different between the SomnoDent $(-0.5 \pm 0.6)$ and TAP group $(-1.3 \pm 1.5)(P<.01)$, and between the TAP and CPAP group $(-0.1 \pm 0.6)(P<.01)$ (Table 1).

No significant association was observed between the amount of mandibular protrusion and the change in overbite and overjet in the SomnoDent group. In the TAP group; however, a significant correlation was observed between the change in overbite and the amount of mandibular protrusion $(\beta=-0.02$; 95\% confidence interval -0.04 to 0.00 ) (Table 1 ).

When evaluating cuspid and molar occlusion, it was observed that in most patients occlusion did not change. In addition, no significant differences were found between the three groups. When evaluating the direction of the occlusal shift, in most cases a mesial direct movement of mandibular teeth was observed (Table 2).
In both MAD groups no differences were observed in crowding of the upper and lower dental arches. In the CPAP group crowding in the upper arch decreased in 1 patient and in both arches in another patient, whereas crowding in the lower arch increased in a third patient. In the SomnoDent group, a decrease in interproximal space in the upper arch was observed in 1 patient (3\%) and an increase in interproximal space in the upper arch was observed in 2 patients (6\%). A decrease in interproximal space in the lower arch was observed in 3 patients (9\%). In the TAP group, a decrease in interproximal space in the upper arch was observed in 2 patients (7\%), and an increase in interproximal space in the upper arch was observed in 2 patients (7\%). An increase in interproximal space in the lower arch was observed in 7 patients (23\%). In the CPAP group, an increase in interproximal space in the upper arch was observed in 1 patient (3\%), and an increase in interproximal space in the lower arch was observed in 4 patients (12\%).

\section{DISCUSSION}

In this study we compared long-term side effects on dental occlusion between different treatment modalities in patients with OSA. We observed that CPAP and both MADs resulted in significant dental changes with long-term use. However, the changes in overjet and anterior-posterior movement in the SomnoDent and CPAP group were less pronounced than the changes observed in the TAP group.

When evaluating baseline characteristics, a distinct difference is observed in the AHI between the different treatment groups. Because Doff et al. ${ }^{29}$ also included patients with more severe OSA, a significant difference was observed between the SomnoDent $(17.5 \pm 13.2)$ and TAP group $(35.6 \pm 22.3)$ and between the SomnoDent and CPAP group (44.2 \pm 5.7$)$, respectively. These significant differences may influence the outcomes of this study. Previous studies have reported that the higher the baseline AHI, the higher percentage mandibular protrusion

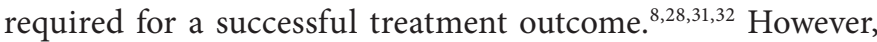
when evaluating the percentage of protrusion in both MAD groups, no significant differences were observed between the TAP and SomnoDent group.

Also, a significant difference in follow-up AHI after 2 to 3 months was observed between the SomnoDent versus the TAP group. This phenomenon may have resulted from the difference in oral appliance design. The TAP appliance has a fixed screw mechanism in the front that is associated with minimal mouth opening possibility. The SomnoDent appliance consists of two separate parts that allow for mouth opening as a result of autorotation of the mandible during sleep. This phenomenon may explain why the AHI after 2 to 3 months was on average significantly higher in the SomnoDent group. In addition, this may also explain why fewer dental side effects were observed in the SomnoDent group. The autorotation of the mandible during sleep could have resulted in less force transmitted to the teeth, resulting in fewer dental side effects.

In the current study a significant decrease in the number of occlusal contact points was seen in the (pre)molar region. This phenomenon was not only observed in both MAD groups, but also in the CPAP group. As demonstrated previously, a 
Table 1-Baseline characteristics, therapeutic use, and cast analysis of the SomnoDent, TAP, and CPAP groups.

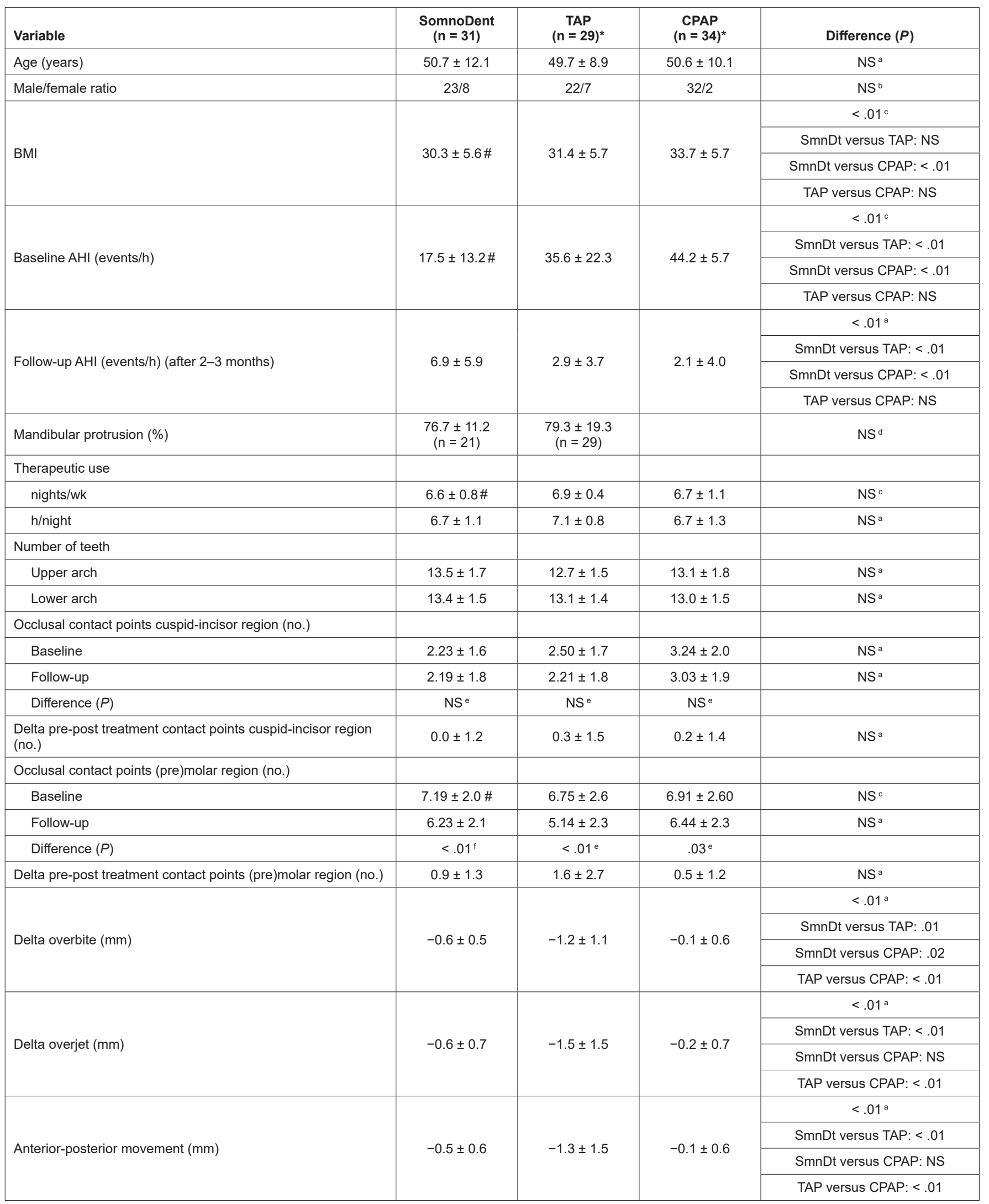

Values are presented as mean \pm standard deviation. ${ }^{*}=$ from Doff et al. ${ }^{29} \#=$ not normally distributed values. Superscript letters indicate the following tests: $\mathrm{a}=$ analysis of variance, $\mathrm{b}=\mathrm{x}^{2}, \mathrm{c}=$ Mann-Whitney $U$ and Kruskal-Wallis tests, $\mathrm{d}=$ independent $t$ test, $\mathrm{e}=$ paired samples $t$ test, $\mathrm{f}=$ Wilcoxon signed-rank test. $\mathrm{AHI}=$ apnea-hypopnea index, BMI = body mass index, CPAP = continuous positive airway pressure, NS = not significant, $\mathrm{SmnDt}=$ SomnoDent, $\mathrm{TAP}=$ Thornton Adjustable Positioner. 
Table 2-Angle classification change.

\begin{tabular}{|l|c|c|c|c|c|}
\hline \multirow{2}{*}{ Patient Group } & \multicolumn{2}{|c|}{$\begin{array}{c}\text { Left Side Angle Classification } \\
\text { Number of Patients }\end{array}$} & \multicolumn{2}{|c|}{$\begin{array}{c}\text { Right Side Angle Classification } \\
\text { Number of Patients }\end{array}$} \\
\cline { 2 - 6 } & Occlusion & Unchanged & Mesial Shift & Unchanged & Mesial Shift \\
\hline \multirow{2}{*}{ SomnoDent $(n=31)$} & Cuspid & 26 out of $30(87 \%)$ & 3 out of $4(75 \%)$ & 28 out of $31(90 \%)$ & 3 out of $3(100 \%)$ \\
\cline { 2 - 6 } & Molar & 28 out of $30(93 \%)$ & 2 out of $2(100 \%)$ & 24 out of $27(89 \%)$ & 3 out of $3(100 \%)$ \\
\hline \multirow{2}{*}{ TAP $(n=29)$} & Cuspid & 21 out of $29(72 \%)$ & 8 out of $8(100 \%)$ & 22 out of $28(79 \%)$ & 6 out of $6(100 \%)$ \\
\hline \multirow{2}{*}{ CPAP $(n=34)$} & Molar & 16 out of $20(80 \%)$ & 3 out of $4(100 \%)$ & 17 out of $21(81 \%)$ & 4 out of $4(100 \%)$ \\
\cline { 2 - 6 } & Cuspid & 28 out of $30(93 \%)$ & 1 out of $2(50 \%)$ & 29 out of $33(88 \%)$ & 3 out of $4(75 \%)$ \\
\cline { 2 - 6 } & Molar & 20 out of $23(87 \%)$ & 1 out of $3(33 \%)$ & 25 out of $28(89 \%)$ & 1 out of $3(33 \%)$ \\
\hline
\end{tabular}

$\mathrm{CPAP}=$ continuous positive airway pressure, TAP $=$ Thornton Adjustable Positioner.

decrease in overjet and overbite may result from long-term MAD therapy. ${ }^{20,21,25,27,29,30}$ As a result of this phenomenon fewer contact points may occur with long-term MAD use. ${ }^{25,29,36}$ However, this does not explain the difference in occlusal contact points with long-term CPAP therapy. CPAP therapy does not protrude the mandible. However, changes in the number of occlusal contact points in the CPAP group may also occur as a result of a tight fitting and therefore large pressure of the nasal mask on the frontal part of the maxilla, which may result in a retroinclination of the maxillary incisors. ${ }^{37}$ Because of this phenomenon a slight autorotation of the mandible may occur, which explains the alteration in number of occlusal contact points. ${ }^{20,21,25,27,29,30}$

All analyses in the current study were manually done by the same observer on dental plaster casts. We used this methodology because it was in line with the previously performed study by Doff et al. ${ }^{29}$ All measurements were done three times by the same observer. Mean values of the second and third measurement were used for further analysis. A previously performed randomized clinical trial has shown that manual model analysis has the same methodological accuracy as digital model analysis. ${ }^{38}$ We believe these aspects have minimalized the margin of error in the current study.

MAD and CPAP therapy is usually considered a lifelong requisite. With that in mind side effects are important to monitor. In the current study a significant decrease is seen in a number of occlusal contact points, overbite, overjet, and anterior-posterior movement, not only in the MAD groups but also in the CPAP group. In the TAP group an association was observed between the decrease in overbite and the percentage of mandibular protrusion. This correlation was not observed in the SomnoDent group. In the TAP group the percentage of mandibular protrusion was obtained from every patient, whereas in the SomnoDent group, in one-third of the patients, the data on mandibular protrusion were missing. This may explain why a significant correlation, between changes in dental occlusion and the percentage mandibular protrusion in the SomnoDent group, was not observed.

When the delta overjet was compared between the different treatment modalities, a significant difference was observed between the TAP and SomnoDent group and between the TAP and CPAP group, respectively. A similar phenomenon was observed with anterior-posterior movement. From these observations it appears that the three treatment modalities result in changes in the overjet and anterior posterior movement of the mandible, which are less pronounced in the SomnoDent and CPAP group. Furthermore, a more pronounced mesial movement in occlusion was observed in the SomnoDent and the TAP groups, respectively, when compared to the CPAP group. In the MAD group, more patients shifted from an Angle Class I to III occlusion or from an Angle Class II to I or III occlusion. It must be mentioned that data on mandibular protrusion were missing in a substantial proportion of the patients in the SomnoDent group. This fact hampers robust conclusions on this phenomenon.

When the results from the current study are compared with those of previous studies, similar changes in dental occlusion, as a result of long-term MAD therapy, have been observed. Some studies describe a change in overbite and overjet, ${ }^{20,21,25,27,30,39}$ whereas others observe a change in anteriorposterior movement. ${ }^{33,40}$ However, not all studies found significant changes in overbite and overjet with long-term MAD therapy ${ }^{39}$ These differences in changes in overbite and overjet between different studies might, in addition to other variables, be explained by differences in MAD design. The MADs evaluated in the current study had a full arch coverage, whereas in the study of Ringqvist et al. ${ }^{39}$ the MAD only covered the (pre) molars. This might result in less force on the frontal part of the dental arches, resulting in fewer changes in overbite and overjet.

The observed differences between the TAP and SomnoDent group could be explained by the difference in mechanism contacting the upper and lower jaw. With the TAP, a fixed screw in the frontal part of the upper appliance connects both parts of the appliance. In the case of the SomnoDent, this is accomplished by two stabilizing blocks in the (pre)molar region of the upper appliance. It could be hypothesized that with the TAP relatively more force is applied to the frontal part of the upper and lower dental arches. This phenomenon may partly explain the difference in delta overbite and delta overjet and anterior-posterior movement between the two groups. In addition, the materials from which the appliances are made may also explain the observed differences in delta overbite and delta overjet between both appliances. The TAP was made of 
hard acrylic, whereas the SomnoDent consisted of hard acrylic on the outside with a soft lining on the inside of the appliance. It could be hypothesized that as a result of the latter feature, less force is transferred to the individual teeth resulting in less changes in overbite and overjet. However, because data on mandibular protrusion were missing in a substantial proportion of patients in the SomnoDent group, differences between both MAD groups in this variable may also explain the observed difference in dental changes. Definite conclusions on the effect of appliance design on changes in dental occlusion can therefore not be drawn based on the data from this study. In addition, other factors such as periodontal health and vertical skeletal characteristics were not taken into account and could also be responsible for the observed differences.

The correlation we observed between the baseline AHI and the amount of mandibular protrusion following titration of the appliances has been described before. A higher baseline AHI requires more mandibular protrusion to reach a successful treatment outcome. ${ }^{8,28,31,32}$ However, it is likely that an increased amount of mandibular protrusion will also result in more dental side effects. ${ }^{8,24,33}$ In this study a significant difference was observed in baseline AHI between the TAP and SomnoDent appliance, with the TAP group having a higher baseline AHI. However, the percentage of mandibular protrusion did not correlate with the baseline AHI in both MAD groups. This may have been the result of the relative small sample size of both MAD groups.

The changes in transverse relation were not pronounced in the current study in all three treatment groups. Therefore, MAD or CPAP therapy does not appear to have a significant effect on the transverse relationships in the maxillary and mandibular dental arches. This may be explained by the fact that the force of both a MAD and a CPAP mask is mainly applied on the frontal aspect of the dental arches, which has few effects on transverse relationships.

Another aspect requiring discussion is the effect of treatment on the Angle classification. In the previous study by Doff et al., changes in Angle classification were observed. ${ }^{29}$ A mesial shift of the lower dental arch relative to the upper dental arch was generally observed. However, not all occlusal changes should be regarded as negative changes. The most favorable occlusal pattern for patients is an Angle Class I occlusion. ${ }^{35}$ It could be unfavorable to change an Angle Class I occlusion into an Angle Class III occlusion. However, when a patient starts with an Angle Class II occlusion and the lower arch shifts forward resulting in an Angle Class I occlusion, these changes may be regarded as favorable. Previous research regarding long-term side effects of a MAD observed that the orthodontic side effects could be classified as "favorable" in $41 \%$ of patients. ${ }^{30}$ In the current study no Angle Class change was observed in $91 \%$ of the molar measurements and in $89 \%$ of the cuspid measurements of the SomnoDent group. However, in the study of Almeida et al., including 70 patients, no changes in the Angle Class were observed only in $14 \%$ of patients. ${ }^{30}$ These differences may be explained by the followup period which was 2 years in the current study and 7.4 years in the study by Almeida et al. ${ }^{30}$ In addition, because we do not know how progressive these changes are, no changes in dental occlusion should always be preferred over "favorable" changes in dental occlusion.

Finally, it is important to use a strict selection procedure when selecting patients for a MAD. First, dental health has to be adequate and, second, enough healthy teeth have to be present in order to stabilize the appliance. Therefore the possible dental changes will be kept to a minimum. It is important that dental practitioners pay attention to possible dental changes with MAD therapy. If these changes are unfavorable or too prominent, an alternative intervention must be considered. Conversely, it should also be noted that CPAP, over the long term, may also result in similar changes in the dental occlusion.

It must be kept in mind that OSA is a sleep-related breathing disorder that usually requires lifelong treatment. Therefore, it is important to pay attention to the therapeutic side effects with long-term CPAP or MAD use. Within the limitations of the current study we observed that TAP and SomnoDent as well as CPAP therapy resulted in significant dental changes with long-term use. Changes in overjet and anterior-posterior movement as a result of the SomnoDent and CPAP therapy appear to be less pronounced when compared with the TAP group. Specific features in oral appliance design may therefore affect the extent of changes in dental occlusion. However, other factors such as periodontal health and vertical skeletal characteristics were not taken into account and could also be responsible for the observed differences. It should also be noted that AHI reductions in the SomnoDent group were also significantly less than in the other two groups. Nevertheless, it is important to pay attention to possible dental side effects during MAD therapy. Before treatment, patients should be informed about the possible dental changes and they should be subjected to a strict examination.

\section{REFERENCES}

1. Jenkinson C, Davies RJ, Mullins R, Straddling JR. Comparison of therapeutic and subtherapeutic nasal continuous positive airway pressure for obstructive sleep apnoea: a randomised prospective parallel trial. Lancet. 1999;353(9170):2100-2105.

2. Sullivan CE, Issa FG. Obstructive sleep apnea. Clin Chest Med. 1985;6(4):633-650.

3. Epstein LJ, Kristo D, Strollo PJ, et al. Clinical guideline for the evaluation, management and long-term care of obstructive sleep apnea in adults. J Clin Sleep Med. 2009;5(3):263-276.

4. de Britto Teixeira A, Abi-Ramia L, de Oliveira Almeida M. Treatment of obstructive sleep apnea with oral appliances. Prog Orthod. 2013;14:10.

5. Flemons WW. Clinical practice. Obstructive sleep apnea. N Engl J Med. 2002;347(7):498-504.

6. Hoekema A, Stegenga B, Wijkstra P, van der Hoeven J, Meinesz A, de Bont L. Obstructive sleep apnea therapy. J Dent Res. 2008;87(9):882-887.

7. Marin JM, Carrizo SJ, Vicente E, Agusti AG. Long-term cardiovascular outcomes in men with obstructive sleep apnoeahypopnoea with or without treatment with continuous positive airway pressure: an observational study. Lancet. 2005;365(9464):1046-1053.

8. Ferguson KA, Cartwright R, Rogers R, Schmidt-Nowara W. Oral appliances for snoring and obstructive sleep apnea: a review. Sleep. 2006;29(2):244-262.

9. Bradley T, Floras J. Obstructive sleep apnoea and its cardiovascular consequences. Lancet. 2009;373(9657):82-93. 
10. Sleep-related breathing disorders in adults: recommendations for syndrome definition and measurement techniques in clinical research. The Report of an American Academy of Sleep Medicine Task Force. Sleep. 1999;22(5):667-689.

11. Kushida CA, Morgenthaler TI, Littner MR, et al. Practice parameters for the treatment of snoring and obstructive sleep apnea with oral appliances: an update for 2005. Sleep. 2006;29(2):240-243.

12. Malhotra A, White DP. Obstructive sleep apnoea. Lancet. 2002;360:(9328)237-245.

13. Hoekema A, Wijkstra PJ, Buiter CT, van der Hoeven JH, Meinesz AF, de Bont LGM. Treatment of the obstructive sleep-apnea syndrome in adults. Ned Tijdschr Geneeskd. 2003;147(49):2407-2412.

14. Sullivan CE, Issa F, Berthon-Jones M, Eves L. Reversal of obstructive sleep apnoea by continuous positive airway pressure applied through the nares. Lancet. 1981;1(8225):862-865.

15. Giles TL, Lasserson TJ, Smith BJ, White J, Wright J, Cates CJ. Continuous positive airways pressure for obstructive sleep apnoea in adults. Cochrane Database Syst Rev. 2006;CD001106.

16. Doff MH, Hoekema A, Wijkstra PJ, et al. Oral appliance versus continuous positive airway pressure in obstructive sleep apnea syndrome: a 2-year follow-up. Sleep. 2013;36(9):1289-1296.

17. Sawyer AM, Gooneratne NS, Marcus CL, Ofer D, Richards KC, Weaver TE. A systematic review of CPAP adherence across age groups: clinical and empiric insights for developing CPAP adherence interventions. Sleep Med Rev. 2011;15(6):343-356.

18. Lim J, Lasserson TJ, Fleetham J, Wright J. Oral appliances for obstructive sleep apnoea. Cochrane Database Syst Rev. 2006;CD004435.

19. Chan AS, Lee RW, Cistulli PA. Dental appliance treatment for obstructive sleep apnea. Chest. 2007;132(2):693-699.

20. Akssam G, Irmtrud EJ, Edmund CR. Dental side effects of mandibular advancement appliances - a 2-year follow-up. J Orofac Orthop. 2008;69(6):437.

21. Hoffstein V. Review of oral appliances for treatment of sleepdisordered breathing. Sleep Breath. 2007;11(1):1-22.

22. Hoekema A, Stegenga B, De Bont LG. Efficacy and co-morbidity of oral appliances in the treatment of obstructive sleep apnea-hypopnea: a systematic review. Crit Rev Oral Biol Med. 2004;15(3):137-155.

23. Sutherland K, Vanderveken OM, Tsuda H, et al. Oral appliance treatment for obstructive sleep apnea: an update. J Clin Sleep Med. 2014;10(2):215-227.

24. Doff MH, Veldhuis SK, Hoekema A, et al. Long-term oral appliance therapy in obstructive sleep apnea syndrome: a controlled study on temporomandibular side effects. Clin Oral Investig. 2012;16(3):689-697.

25. Martínez-Gomis J, Willaert E, Nogues L, Pascual M, Somoza M, Monasterio C. Five years of sleep apnea treatment with a mandibular advancement device. Side effects and technical complications. Angle Orthod. 2010;80(1):30-36.

26. Fritsch KM, Iseli A, Russi EW, Bloch KE. Side effects of mandibular advancement devices for sleep apnea treatment. Am J Respir Crit Care Med. 2001;164(5):813-818.

27. Hammond RJ, Gotsopoulos H, Shen G, Petocz P, Cistulli PA, Darendeliler MA. A follow-up study of dental and skeletal changes associated with mandibular advancement splint use in obstructive sleep apnea. Am J Orthod Dentofacial Orthop. 2007;132(6):806-814.

28. Walker-Engström ML, Ringqvist I, Vestling O, Wilhelmsson B, Tegelberg A. A prospective randomized study comparing two different degrees of mandibular advancement with a dental appliance in treatment of severe obstructive sleep apnea. Sleep Breath. 2003;7(3):119-130.

29. Doff MH, Finnema KJ, Hoekema A, Wijkstra PJ, de Bont LG, Stegenga B. Long-term oral appliance therapy in obstructive sleep apnea syndrome: a controlled study on dental side effects. Clin Oral Investig. 2013;17(2):475-482.
30. Almeida FR, Lowe AA, Otsuka R, Fastlicht S, Farbood M, Tsuiki S. Long-term sequellae of oral appliance therapy in obstructive sleep apnea patients: Part 2. Study-model analysis. Am J Orthod Dentofacial Orthop. 2006;129(2):205-213.

31. Robertson C, Herbison P, Harkness M. Dental and occlusal changes during mandibular advancement splint therapy in sleep disordered patients. Eur J Orthod. 2003;25(4):371-376.

32. Kato J, Isono S, Tanaka A, et al. Dose-dependent effects of mandibular advancement on pharyngeal mechanics and nocturnal oxygenation in patients with sleep-disordered breathing. Chest. 2000;117(4):1065-1072.

33. Aarab G, Lobbezoo F, Hamburger HL, Naeije M. Effects of an oral appliance with different mandibular protrusion positions at a constant vertical dimension on obstructive sleep apnea. Clin Oral Investig. 2010;14(3):339-345.

34. Marklund M, Franklin K, Persson M. Orthodontic side-effects of mandibular advancement devices during treatment of snoring and sleep apnoea. Eur J Orthod. 2001;23(2):135-144.

35. Angle EH. Treatment of Malocclusion of the Teeth. Angle's System. 7th ed. Philadelphia, PA: The S.S. White Dental Manufacturing Company; 1907.

36. Otsuka R, Almeida F, Lowe A. The effects of oral appliance therapy on occlusal function in patients with obstructive sleep apnea: a short-term prospective study. Am J Orthod Dentofacial Orthop. 2007;131(2):176-183.

37. Doff MH, Hoekema A, Pruim GJ, Huddleston Slater JJ, Stegenga B. Long-term oral-appliance therapy in obstructive sleep apnea: a cephalometric study of craniofacial changes. J Dent. 2010;38(12):1010-1018.

38. Lippold C, Kirschneck C, Schreiber K, et al. Methodological accuracy of digital and manual model analysis in orthodontics - a retrospective clinical study. Comput Biol Med. 2015;62:103-109.

39. Ringqvist M, Walker-Engström ML, Tegelberg A, Ringqvist I. Dental and skeletal changes after 4 years of obstructive sleep apnea treatment with a mandibular advancement device: a prospective, randomized study. Am J Orthod Dentofacial Orthop. 2003;124(1):53-60.

40. Chen H, Lowe AA, de Almeida FR, Fleetham JA, Wang B. Threedimensional computer-assisted study model analysis of long-term oral-appliance wear. Part 2. Side effects of oral appliances in obstructive sleep apnea patients. Am J Orthod Dentofacial Orthop. 2008;134(3):408-417.

\section{SUBMISSION \& CORRESPONDENCE INFORMATION}

Submitted for publication June 23, 2017

Submitted in final revised form September 28, 2017

Accepted for publication October 10, 2017

Address correspondence to: J.A.M. Uniken Venema, Department of Oral Kinesiology, Academic Centre for Dentistry Amsterdam (ACTA), University of Amsterdam and VU University Amsterdam, MOVE Research Institute Amsterdam, Amsterdam, The Netherlands; Tel: +3120 5980380; Fax: +3120 5980333; Email: j.a.m.unikenvenema@acta.nl

\section{DISCLOSURE STATEMENT}

Work for this study was performed at the University Medical Center Groningen. The authors report no conflicts of interest. 